\title{
Natural regeneration of tropical rain forest in Suriname as a land-use option
}

\author{
N. R. de Graaf (Department of Silviculture and Forest Ecology, Agricultural Uni- \\ versity, P.O. Box 342, 6700 AH Wageningen, Netherlands)
}

Received 20 May 1986; accepted 31 October 1986

\begin{abstract}
The need for management of tropical rain forest in Suriname, and possibilities of a polycyclic system in natural forest are discussed. The system, essentially a controlled harvesting followed by silvicultural treatments, probably will be a more sustainable and better land-use than shifting cultivation or plantation forestry, and will create permanent jobs and produce an export product.
\end{abstract}

Introduction. Exploitation for commercial timber of the tropical rain forest in Suriname as well as in many other parts of South America, takes only a small volume from the primary forest, leaving a forest only partly damaged. Negative influences on the forest of such harvesting are small as compared with the situation in many parts of South-east Asia where large volumes of timber are taken per ha. Clearing for shifting cultivation followed by use as low-quality pasture is not yet widespread in Suriname.

To conserve these forests, they must be managed actively. A continuous production of valuable raw material is needed in most cases to finance such management, since non-material benefits usually are highly praised but not adequately rewarded. Consequently, silvicultural methods have to be at disposal to assure sustained yields from forests after first exploitation.

Forestry in the Forestry Belt of Suriname. In Suriname, sustained forestry development is planned for the so-called Forestry Belt, a continous zone of about $1.5 \times 10^{6}$ ha of economically accessible forests, between the wet and poorly drained coastal area, and the steep hills and mountains of the interior (Vink, 1970). Here some $2000 \mathrm{~km}$ of gravel roads have already been built, and many forestry experiments have been carried out.

An important socio-economic factor in the Forestry Belt is the lack of population, which makes labour expensive and land resources cheap. After the opening up of the area in the past thirty years, the timber industry has already selectively harvested the better part of the Forestry Belt.

When no management decision is taken about once exploited natural forests, the timber industry will simply return to these areas for a next harvest. It will then harvest the timber rejected as being second-class at first exploitation, some first-quality timber overlooked the first time, plus a minimum additional volume of species considered first-class that have grown to commercial size since first exploitation. 
This type of use hardly deserves the name of management. It leads to further degradation of the forest, as gradually less commercially interesting timber will be available. At the moment about 50 species are on the list of accepted commercial species, and further extension is not expected.

It has been known a long time that increment of commercial species in the high dryland forest is not substantially raised by effects of the first restricted harvesting (Boerboom, 1964). Silvicultural measures have to be taken to maintain the proportion of commercial species in the stand and to obtain a second harvest within a reasonably short period. Long periods between harvests mean high cost for patrolling and maintenance of infrastructure, and a low increment rate means low timber production for the forest industry.

Apart from management of natural forest other approaches have been tried. Forest plantations of fast-growing multiple-use species such as Caribbean pine have been partly successful (Boxman et al., 1985). Converting exploited natural forest with strip planting methods was started on a semi-practical scale, but proved labour-intensive and complicated to manage, besides being not very productive.

The Celos Silvicultural System. A silvicultural system has to combine ecological and socio-economic factors in a technically feasible method. In the tropical high dryland forest of Suriname there is an ecological need for maintaining a high biomass, as ecosystem productivity depends mainly on efficient nutrient cycling and conservation in biomass rather than on soil fertility of the chemically poor and structurally vulnerable soils of the Forestry Belt. Natural forest, when manipulated moderately, is assumed to be superior in nutrient conservation compared to plantation forest. The highly mixed and unevenaged character of the natural forest is an economic disadvantage, but is ecologically desirable for stability. This character should be preserved in managed forest, though for reason of economics it has to be reduced to a certain extent.

Research in management of natural dryland forest has been carried out by the Forest Service of Suriname since the early 1950s, and by the Centre for Agricultural Research in Suriname (CELOS) since 1965. Originally the research was directed at the development of a monocyclic system, i.e. with a final felling at the end of a period during which the trees in the stand have developed from seedlings into mature trees. With such systems the manipulation of the stand components was rated to be easier and more rewarding than in polycyclic systems (Boerboom, 1964). Furthermore, a large volume of standing valuable timber per ha was assumed to be desirable and also possible to attain.

However, the many treatments and the long period needed to reach this goal make the monocyclic approcach an expensive one. Moreover, the destructive harvest of such a large timber volume would certainly result in an unproductive type of secondary bush to start the second cycle with. A polycyclic system would be able to use the advance growth of valuable species present in cut-over stands, and make it possible to harvest in relatively short cycles. Treatment thus bears less cost of interest. The polycyclic system chosen also absorbs less labour and capital input, enabling the forest manager to follow closely the harvesting operations with silvicultu- 
ral treatments, on the same scale. In this way a larger area of forest can be brought under regular management than with intensive methods.

Polycyclic systems in broad-leaved forest have the handicap of the harvesting damage which restricts the amount of trees that can be taken. Only first-class stems should be selected for extraction, leaving at the same time a good number of trees to continue production of valuable wood species. When this restriction in harvesting is accepted, the ecological advantages are undeniable, as the tree-by-tree regeneration processes in primary forest can be closely imitated in forest management. Most important, the biomass of the forest ecosystem can be kept much higher with polycyclic than with monocyclic systems.

Based on these principles the Celos Silvicultural System has been developed, which was shortly described in this journal by Boxman et al. (1985). It must be seen as transitional to a selection system in future, when timber will be more scarce and bring a better price. Until that stage, the natural forest areas destined for timber production have to be made more productive than they are now under purely 'harvesting management'.

The main characteristics of the natural forest are only partly changed by the silvicultural treatments. Hydrological impacts are small, and mainly caused by roadbuilding. Forest fire risks are as low as for the natural forest. Occurrence of treedwelling species of plants as well as animals may be reduced by elimination of great numbers of large trees. However, effects of such reduction in numbers of large trees of non-commercial species on ecological stability or on long-term productivity of the ecosystem have as yet not been observed. It is believed that such effects will occur only after long periods of drastic refinement regimes.

Socio-economic and planning aspects. The ecological effects being moderate, the socio-economic considerations should receive further attention. The Celos Management System (CMS), an integration of Celos Harvesting System and Celos Silvicultural System (see also Boxman et al., 1985) was made to fit the regional conditions in the Forestry Belt of Suriname. The sustained and efficient production of timber as a valuable crop for local use and export is thought to be superior to agricultural use of the poor tropical soils. Especially the very extensively used pasture often following shifting cultivation in other parts of the American tropical rain forest biome compares unfavourably with the CMS, not only in ecological terms, but also in terms of supplying sustained labour opportunities and income generation.

The concept of biomass-dependent site quality as used in the CMS has not yet been recognized by many people involved in land-use planning, although traditional shifting cultivators already used it from time immemorial. The overruling concept of bare soil as one of the basic production factors, which stems from soil science and agricultural systems in temperate climates, may be the main obstacle to better ways of thought.

The government and the trade and industry have to procure an infrastructure for the application of the CMS, which means that active planning must be done. Direct problems in applying the system in Suriname are the costs involved with the silvicultural treatments, as the industry is accustomed to only very low royalties for its 
timber. Also the set-up of an organization to control the logging and carry out the silvicultural work will take time. The timber industry however has a lot to win with accepting this approach of forest management, as exhaustion of the timber supplies jeopardizes its very existence. The area on which the system could function ultimately is rated at about half a million hectares in the Forestry Belt, which could on a sustained yield base supply nearly twice the actual annual harvest taken over the last decade.

For the total rain forest area in South America such an estimate of potential area is difficult, but a bold assumption is that one third of the area might finally be used under management systems such as the CMS, one third should be put under strict nature reserve management or left for hunting/gathering and one third used for more intensive agricultural and forestry plantations, mainly with tree-based crops planted on soils of reasonable or better quality.

\section{References}

Boerboom, J. H. A., 1964. De natuurlijke regeneratie van het Surinaamse mesofytische bos na uitkap. Landbouwhogeschool, Wageningen.

Boxman, O. et al., 1985. Towards sustained timber production from tropical rain forests in Suriname. Netherlands Journal of Agricultural Science 33: 125-132.

Vink, A. T., 1970. Forestry in Suriname. Forest Service, Paramaribo, Suriname.

This synopsis is based on the first two parts of a doctoral thesis entitled 'A silvicultural system for natural regeneration of tropical rain forest in Suriname', Agricultural University, Wageningen, 1986. 250 pp., figs, tables, refs.

Available as paper copy (order R064P, $f 40$ including postage) at: NARD, clo Pudoc, P.O.Box 4, 6700 AA Wageningen, Netherlands (telex $45015 \mathrm{blhwg}$ ). 